\title{
Indirect Fluorometric Determination of Diclofenac Sodium
}

\author{
Marcela A. CASTILlo*,** and Liliana BRUZzone*广 \\ *División Química Analítica, Facultad de Ciencias Exactas, Universidad Nacional de La Plata, \\ Calle 47 esq. 115, 1900 La Plata, Argentina \\ **CIDEPINT, 52 e/121 y 122, 1900 La Plata, Argentina
}

\begin{abstract}
A simple and easy method of analysis for diclofenac sodium is reported. A spectrofluorometric method for the microdetermination of diclofenac sodium has been developed through its reaction with cerium(IV) in an acidic solution and measurement of the fluorescence of the $\mathrm{Ce}$ (III) ions produced. Under the optimum experimental conditions for the oxidation reaction, $1.0 \mathrm{M} \mathrm{H}_{2} \mathrm{SO}_{4}$ with $90 \mathrm{~min}$ of heating time $\left(100^{\circ} \mathrm{C}\right)$, the range of application is $124.3-600 \mathrm{ng} \mathrm{mL}^{-1}$ and the limit of detection is $72.7 \mathrm{ng} \mathrm{mL}^{-1}$. The proposed method was applied to the determination of diclofenac sodium in pharmaceutical tablets. The results of the analysis show a good agreement with those obtained by the official USP 27 HPLC method.
\end{abstract}

(Received June 29, 2005; Accepted July 25, 2005)

\section{Introduction}

Diclofenac, [o-[(2,6-dichlorophenyl)amino]phenyl] acetic acid belongs to a class of drugs called nonsteroidal antiinflammatory drugs (NSAIDs). In pharmacologic studies, diclofenac has shown anti-inflammatory, analgesic, and antipyretic activity. As with other NSAIDs, its mode of action is not known; its ability to inhibit prostaglandin synthesis, however, may be involved in its anti-inflammatory activity, as well as contributing to its efficacy in relieving pain related to inflammation and primary dysmenorrhea. With regard to its analgesic effect, diclofenac is not a narcotic.

Diclofenac is used in treating osteoarthritis, rheumatoid arthritis, and ankylosing spondylitis. Due to its low solubility, it is commercially available as its sodium salt. A number of analytical methods have been developed for the quantitative determination of this drug in dosage forms and in biological samples. Among these are spectrophotometry, ${ }^{1,2}$ fluorometry, ${ }^{3-5}$ chromatography ${ }^{6-9}$ and, recently, some electrochemical sensors have been developed. ${ }^{10,11}$ USP $27^{12}$ describes a reversed-phase HPLC method based on UV detection for its determination.

The aim of this study is to elaborate a simple and not expensive method for the assay of diclofenac in pharmaceutical preparations. The method is based on oxidation of the drug by an excess of $\mathrm{Ce}(\mathrm{IV})$ with a subsequent fluorometric measurement.

$\mathrm{Ce}(\mathrm{IV})$ is a well-known oxidizing agent, and has been used for the fluorometric determination of $\mathrm{As}(\mathrm{III}), \mathrm{Fe}(\mathrm{II})$, oxalate, ${ }^{13,14}$ hydrogen peroxide, ${ }^{15}$ uranium $^{16}$ and some drugs, such as phenothiazines, ${ }^{17}$ ritodrine, ${ }^{18}$ and isoxsuprine. ${ }^{19}$

The method may be affected by coexisting substances, which may be oxidized with $\mathrm{Ce}(\mathrm{IV})$. Examples of the different interferences have been reported. ${ }^{13,14,16-18}$

\footnotetext{
$\dagger$ To whom correspondence should be addressed

E-mail: bruzzone@quimica.unlp.edu.ar
}

\section{Experimental}

\section{Apparatus}

The absorbance was measured on a Shimadzu UV-240 recording spectrophotometer. All recordings of uncorrected fluorescence spectra and fluorometric measurements were carried out on a Perkin-Elmer LS-50B luminescence spectrometer equipped with a pulsed xenon lamp, an R928 photomultiplier tube and a computer working with FL Winlab software. All of the measurements took place in a standard 10 $\mathrm{mm}$ path-length quartz cell with $10 \mathrm{~nm}$ bandwidths for the excitation and emission monochromators.

\section{Reagents and chemicals}

Diclofenac sodium was supplied by Unifarma S.A. (Argentina), the content was determined by the USP 27 method and was found to be $99.4 \%$. Dosage forms containing diclofenac sodium were purchased from a local market. All other reagents were of analytical grade. All solutions were prepared with doubledistilled water. A $1 \times 10^{-2} \mathrm{M}$ stock solution of $\mathrm{Ce}(\mathrm{IV})$ was prepared from cerium ammonium sulfate in $1.0 \mathrm{M}$ sulfuric acid. Diclofenac standard solution. A $20 \mu \mathrm{g} \mathrm{mL}^{-1}$ working standard solution of diclofenac sodium was freshly prepared in doubledistilled water.

\section{Procedure}

General procedure. A $1 \times 10^{-2} \mathrm{M}$ stock solution of $\mathrm{Ce}(\mathrm{IV})$ was diluted with $1.0 \mathrm{M}$ sulfuric acid to give a $1.7 \times 10^{-4} \mathrm{M} \mathrm{Ce}(\mathrm{IV})$ solution; $3.0 \mathrm{~mL}$ of this solution were transferred into separate 12 $\mathrm{mL}$ capped glass vials. To each vial, adequate aliquots $(0-300$ $\mu \mathrm{L}$ ) of diclofenac stock solution and enough water to complete a $3.3 \mathrm{~mL}$ final volume were added. The vials were sonicated for $1 \mathrm{~min}$, and then heated in a thermostated water-bath at $100^{\circ} \mathrm{C}$ for $90 \mathrm{~min}$. The reaction was stopped by cooling the vials in a water-ice bath for at least $15 \mathrm{~min}$. The vials were left standing at room temperature, and the total volume was adjusted to $10 \mathrm{~mL}$ by the addition of water. The relative fluorescence intensity of the solutions was measured at $\lambda_{\mathrm{em}}=356 \mathrm{~nm}$ with $\lambda_{\mathrm{ex}}=250 \mathrm{~nm}$. 


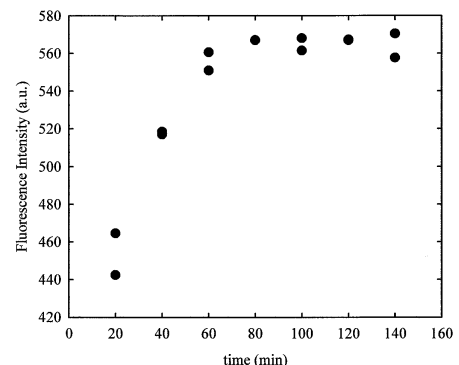

Fig. 1 Effect of the heating time at $100^{\circ} \mathrm{C}$ on the reaction yield (using $300 \mu \mathrm{L}$ of a $20 \mu \mathrm{g} \mathrm{mL}^{-1}$ diclofenac standard solution).

Procedure for tablets. Ten tablets were weighed and ground in a mortar. Twenty milliliters of water were added to a quantity equivalent to $4 \mathrm{mg}$ of diclofenac. The solution was sonicated for $30 \mathrm{~min}$ and filtered through a $0.22 \mu \mathrm{m}$ nylon membrane. The filtrate was placed into a $100.0 \mathrm{~mL}$ volumetric flask and diluted with water.

To each vial containing $3.0 \mathrm{~mL}$ of a $1.7 \times 10^{-4} \mathrm{M} \mathrm{Ce}(\mathrm{IV})$ solution in $1.0 \mathrm{M}$ sulfuric acid, a $40 \mu \mathrm{L}$ aliquot of the sample solution was added. Adequate aliquots $(0-260 \mu \mathrm{L})$ of diclofenac stock solution and enough water to complete a 3.3 $\mathrm{mL}$ final volume were added. These solutions were analyzed according to a general procedure, described previously.

\section{Results and Discussion}

Cerium(IV) is a powerful oxidizing agent and is non-fluorescent under acid conditions, while its reduced form exhibits native fluorescence. The latest property has been used for the indirect determination of several drugs. The oxidation of diclofenac sodium with $\mathrm{Ce}(\mathrm{IV})$ is the basis of the present analytical procedure developed for diclofenac determination. The increase in the fluorescence intensity due to $\mathrm{Ce}(\mathrm{III})$ ions formed after the addition of the drug to an acid Ce(IV) solution was measured at $\lambda_{\mathrm{em}}=356 \mathrm{~nm}$ with $\lambda_{\mathrm{ex}}=250 \mathrm{~nm}$.

\section{Optimization of experimental variables}

A series of investigations were carried out to establish the optimum experimental conditions for the oxidation. The optimized parameters included the $\mathrm{Ce}(\mathrm{IV})$ concentration, temperature and heating time, acidity of the medium.

Cerium(IV) concentration. The concentration of the Ce(IV) was chosen to avoid any inner filter effects when measuring the fluorescence of the final solutions. The absorbances must lie under 0.05 at the excitation and emission maxima.

The optimum Ce(IV) molar concentration to the diclofenac molar concentration ratio must be over 25 .

Effect of temperature and heating time. At room temperature the oxidation reaction of diclofenac sodium with $\mathrm{Ce}$ (IV) proceeds slowly. Completeness of the reaction was reached after $24 \mathrm{~h}$. The reaction was monitored by absorbance measurements using high concentrations of both $\mathrm{Ce}(\mathrm{IV})$ in 1.0 $\mathrm{M}$ sulfuric acid and diclofenac sodium. The reaction rate increased when heating the solution.

The heating temperatures were studied in the $80-100^{\circ} \mathrm{C}$ range over 80 min using $300 \mu \mathrm{L}$ of a diclofenac stock solution by monitoring the fluorescence intensity. A $36 \%$ increment in the signal was observed at $100^{\circ} \mathrm{C}$ with respect to $80^{\circ} \mathrm{C}$. Therefore, the recommended condition was to heat at $100^{\circ} \mathrm{C}$ in a thermostated water bath.

Then, different periods of heating time at $100^{\circ} \mathrm{C}$ were

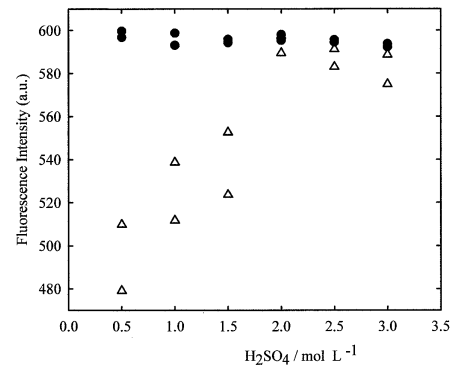

Fig. 2 Effect of the $\mathrm{H}_{2} \mathrm{SO}_{4}$ concentration on the reaction yield (using $300 \mu \mathrm{L}$ of a $20 \mu \mathrm{g} \mathrm{mL}^{-1}$ diclofenac standard solution). Heating time at $100^{\circ} \mathrm{C}:(\bullet) 90 \mathrm{~min} ;(\triangle) 40 \mathrm{~min}$.

analyzed, from 20 to $140 \mathrm{~min}$ (Fig. 1). Although constancy was reached at $80 \mathrm{~min}$ of heating time, $90 \mathrm{~min}$ was chosen in order to assure completeness of the reaction.

Acidity of the medium. The effect of the sulfuric acid concentration on the reaction yield was examined over the range of $0.5 \mathrm{M}$ to $3.0 \mathrm{M} \mathrm{H}_{2} \mathrm{SO}_{4}$. Although no substantial changes in the fluorescence signal were observed after heating at $100^{\circ} \mathrm{C}$ for $90 \mathrm{~min}$, a slight decrease was produced in the $0.5-1.0 \mathrm{M} \mathrm{H}_{2} \mathrm{SO}_{4}$ range and above $2.5 \mathrm{M} \mathrm{H}_{2} \mathrm{SO}_{4}$. A lesser heating time produced minor and scatter signals that increased up to $2.0 \mathrm{M} \mathrm{H}_{2} \mathrm{SO}_{4}$ concentration, with a posterior decrease at higher concentrations (Fig. 2). Therefore, $1.0 \mathrm{M} \mathrm{H}_{2} \mathrm{SO}_{4}$ with $90 \mathrm{~min}$ of heating time was selected to avoid working with high concentrations of the acid.

\section{Quantitative performance}

Results obtained with diclofenac sodium standard. The optimized procedure was applied to $0-300 \mu \mathrm{L}$ aliquots of a 35 $\mu \mathrm{g} \mathrm{mL} \mathrm{m}^{-1}$ diclofenac sodium standard solution.

The final concentration of the standards $\left(C_{\mathrm{i}}\right)$ ranged from 18 to $958 \mathrm{ng} \mathrm{mL}-1$. The response standard deviations at each analyte level $\left(s_{\mathrm{i}}\right)$ were estimated from the replicate values of the fluorescence intensity $\left(F_{\mathrm{i}}\right)$; the homogeneity of the data was confirmed by means of Cochran's test. ${ }^{20}$

A fit of $F_{\mathrm{i}}$ to $C_{\mathrm{i}}$ was carried out by means of a least-squares regression analysis. The $F$-test for the lack of a fit, ${ }^{20}$ at a 0.05 significance level, was used to estimate the linear range of the calibration plot.

The results of the regression analysis through points below the upper limit of the linear range and the values estimated for those limits are gathered in Table 1.

The detection limit was estimated from the prediction bands, following calculation procedures given by Zorn and coworkers. ${ }^{21}$ Its value is compared in Table 1 with that calculated as the analyte concentration, giving a signal equal to the blank signal plus three standard deviations of the blank. ${ }^{22}$ No significant difference between both values could be detected by means of a $t$-test.

The quantitation limit was calculated as the analyte level at which the relative standard deviation $\left(\mathrm{RSD}=s_{\mathrm{i}} / F_{\mathrm{i}}\right)$ is $0.10 .^{23}$

An RSD of $2.1 \%$ was obtained by measuring 10 replicate samples containing $351 \mathrm{ng} \mathrm{mL}^{-1}$ of diclofenac sodium.

\section{Application}

The proposed method was applied to the determination of diclofenac sodium in three pharmaceutical formulations (tablets). They were treated as described under Experimental.

The slopes of the standard calibration line and the standard addition line were compared by means of a $t$-test. ${ }^{20}$ Two of the formulations showed significant differences with the standards, 
Table 1 Results of the least-squares regression of fluorescence intensity $\left(F_{\mathrm{i}} / \mathrm{a} . \mathrm{u}\right.$. $)$ against the diclofenac sodium concentration $\left(C_{\mathrm{i}} / \mathrm{ng}\right.$ $\mathrm{mL}^{-1}$ ), upper limit of the linear range, detection limit and quantitation limit

\begin{tabular}{|c|c|c|c|c|c|c|c|c|}
\hline \multirow{2}{*}{$N^{\mathrm{a}}$} & \multirow{2}{*}{ Intercept $\pm s^{\mathrm{b}}$} & \multirow{2}{*}{ Slope $\pm s^{\mathrm{b}}$} & \multirow{2}{*}{$s_{\mathrm{F} / \mathrm{C}^{\mathrm{c}}}$} & \multirow{2}{*}{$r^{\mathrm{d}}$} & \multirow{2}{*}{ U.L. ${ }^{e}$} & \multicolumn{2}{|c|}{ L.D. ${ }^{f}$} & \multirow{2}{*}{ L.Q. } \\
\hline & & & & & & LSR $^{g}$ & C.A. ${ }^{h}$ & \\
\hline 65 & $76.338 \pm 4.036$ & $0.8561 \pm 0.0116$ & 18.278 & 0.9953 & 600 & 72.7 & 64.0 & 124.3 \\
\hline
\end{tabular}

a. Number of calibration data points. b. Standard deviation. c. Residual standard deviation. d. Correlation coefficient. e. Upper limit of the linear range. f. Detection limit. g. Calculated from the least squares regression analysis. h. Calculated from the classic approach. i. Quantitation limit.

\begin{tabular}{cccc}
$\begin{array}{c}\text { Table 2 } \\
\text { pharmaceutical preparations }\end{array}$ & of & diclofenac & sodium in \\
\hline Sample & $\begin{array}{c}\text { Nominal content } \\
(\mathrm{mg} / \text { tablet })\end{array}$ & $\begin{array}{c}\text { Proposed } \\
\text { method }^{\mathrm{a}}\end{array}$ & $\begin{array}{c}\text { Reference } \\
\text { method }^{\mathrm{b}}\end{array}$ \\
\hline $\mathrm{A}$ & 50 & $51.4 \pm 1.8$ & 51.0 \\
$\mathrm{~B}$ & 50 & $51.6 \pm 3.1$ & 51.8 \\
$\mathrm{C}$ & 75 & $76.9 \pm 4.7$ & 76.5 \\
\hline
\end{tabular}

a. Content calculated from the standard additions and Youden plots. b. HPLC method (USP 27). ${ }^{12}$

which indicates the presence of matrix effects. Calculation methods that enable corrections for these effects must be used for the quantitative evaluation of diclofenac sodium in pharmaceutical formulations. ${ }^{24}$ Therefore, five different portions of the ground tablets were carefully weighed and used to prepare the aqueous solution indicated under Experimental. Then, $40 \mu \mathrm{L}$ aliquots of this solution were treated according to the optimized procedure. The intercepts of the plots of fluorescence intensity against the sample weight (Youden plots) were statistically different from those obtained by the standard addition method.

The contents of diclofenac sodium in each formulation were roughly estimated by means of the corresponding calibration equation. Then, the standard addition method was applied, as indicated under Experimental. Aliquots of $40 \mu \mathrm{L}$ of the sample solutions were spiked at $0,50,100$ and $150 \%$ of the roughly estimated levels for diclofenac sodium. The contents of diclofenac were calculated from the ratio of the difference between the intercepts of the standard additions and the Youden plots to the slope of the standard additions one. The obtained results are listed in Table 2 together with those obtained by the official method (USP 27) ${ }^{12}$ and the nominal contents. A $t$-test revealed that there was no statistical difference between the results obtained using the proposed method and the official one at the $95 \%$ confidence level.

\section{Conclusion}

A very simple and easy method for the analysis of diclofenac sodium has been reported. The developed method is suitable for the routine assay and quality control of pharmaceuticals. Furthermore, this method is less time consuming than the proposed HPLC official method. Due to its sensitivity, the indirect fluorometric method could be applied for the assay of diclofenac in biological fluids.

\section{Acknowledgements}

M. A. C, is a member of the Carrera del Investigador, CONICET (Consejo Nacional de Investigaciones Científicas y Técnicas de la República Argentina).

\section{References}

1. M. A. Christianan and L. Pui-Kai, in "Analytical Profiles of Drug Substances", ed. K. Florey, 1990, Academic Press, New York.

2. J. C. Botello and G. Pérez Caballero, Talanta, 1995, 42, 105.

3. L. A. Carreira, M. Rizk, Y. El Shabrawy, N. A. Zakhari, and S. S. Toubar, J. Pharm. Biomed. Anal., 1995, 13, 1331.

4. P. C. Damiani, M. Bearzotti, M. A. Cabezón, and A. C. Olivieri, J. Pharm. Biomed. Anal., 1999, 20, 587.

5. J. A. Arancibia, M. A. Boldrini, and G. M. Escandar, Talanta, 2000, 52, 261.

6. L. González, G. Yuln, and M. G. Volonté, J. Pharm. Biomed. Anal., 1999, 20, 487.

7. R. Roškar and V. Kmetec, J. Chromatogr., B, 2003, 788, 57.

8. B. X. Mayer, K. Naminarian, P. Dehghanyar, R. Stroh, H. Mascher, and M. Müller, J. Pharm. Biomed. Anal., 2003, 33, 745 .

9. C. Martínez Algaba, L. Escuder Gilabert, S. Sagrado, R. M. Villanueva Camañas, and M. J. Medina Hernández, J. Pharm. Biomed. Anal., 2004, 36, 393.

10. M. C. Blanco López, M. J. Lobo Castañón, A. J. Miranda Ordierez, and P. Tuñón Blanco, Anal. Bioanal. Chem., 2003, 377, 257.

11. M. C. Blanco-López, L. Fernández Llano, M. J. Lobo Castañón, A. J. Miranda Ordierez, and P. Tuñón Blanco, Anal. Lett., 2004, 37, 915.

12. "United States Pharmacopeia, USP-27/NF-22", 2004, Authority of the United States Pharmacopeial Convention, Rockville, 595.

13. G. F. Kirkbright, T. S. West, and C. Woodward, Anal. Chim. Acta, 1966, 36, 298.

14. L. Bruzzone, Aust. J. Educ. Chem., 2003, 61, 14.

15. B. Demirata Öztürk, G. Özen, H. Filik, I. Tor, and H. Afsar, J. Fluorescence, 1998, 8, 185

16. C. Boonpanaid and K. Oguma, Anal. Sci., 2005, 21, 155.

17. T. Pérez-Ruiz, C. Martínez Lozano, V. Tomás, and C. Sidrach de Cardona, Talanta, 1993, 40, 1361.

18. O. A. Razak, J. Pharm. Biomed. Anal., 1998, 18, 359.

19. N. A. A. Alarfaj, J. Pharm. Biomed. Anal., 2002, 28, 331.

20. D. L. Massart, B. G. M. Vandeginste, L. M. C. Buydens, S. De Jong, P. J. Lewi, and J. Smeyers Verbeke, "Handbook of Chemometrics and Qualimetrics: Part A", 1997, Elsevier, Amsterdam.

21. M. E. Zorn, R. D. Gibbons, and W. C. Sonzogoni, Anal. Chem., 1997, 69, 3069.

22. J. N. Miller and J. C. Miller, "Statistics and Chemometrics for Analytical Chemistry", 2000, Pearson Education Limited, Essex.

23. M. A. Castillo and R. C. Castells, J. Chromatogr., A, 2001, 921, 121.

24. R. C. Castells and M. A. Castillo, Anal. Chim. Acta, 2000, $423,179$. 